\title{
Effects of metabolic substrates and ionic environment on in-vitro activation of delayed implanting mouse blastocysts
}

\author{
G. L. Nieder and H. M. Weitlauf \\ Department of Anatomy, Texas Tech University Health Sciences Center, Lubbock, TX 79430 , \\ U.S.A.
}

\begin{abstract}
Summary. The possibility that the embryonic diapause associated with delayed implantation in mice is maintained by limitation of an essential amino acid, energy substrate or concentration of ions was examined by comparing the rates of DNA synthesis in delayed implanting embryos that were 'reactivated' by incubation in 'complete' medium or in one of several specially formulated 'deficient' media. It was found, in agreement with earlier observations, that an increase in the rate of DNA synthesis could be detected within $12 \mathrm{~h}$ and continued through $72 \mathrm{~h}$ in complete medium. An identical pattern was found when embryos were incubated in medium deficient in amino acids and vitamins. Similar patterns of activation were observed in the absence of all metabolizable substrates, a drastically reduced concentration of $\mathrm{Na}^{+}$, and even in a medium consisting only of $25 \mathrm{~mm}$-bicarbonate buffer, $\mathrm{NaCl}$ and $\mathrm{KCl}$. The embryos incubated in the more drastically deficient media appeared to be damaged after 18-24 h. Nevertheless, the observation that the rate of DNA synthesis did not remain depressed suggests that such deficiencies are not the means by which embryonic dormancy is maintained in utero.
\end{abstract}

\section{Introduction}

It has been proposed that the embryonic diapause associated with delayed implantation in mice is due to limited availability of various substrates or ions in the uterine lumen (see McLaren, 1973; Van Blerkom, Chavez \& Bell, 1979, for reviews). Observations cited in support of this proposition have included : (1) the rate of incorporation of $\left[{ }^{35}\right.$ S $]$ methionine into protein increases in delayed implanting embryos placed in vitro but remains low if the culture medium lacks glucose (Van Blerkom et al., 1979); (2) the rates of uptake and incorporation of amino acids are reduced in embryos incubated for $22 \mathrm{~h}$ in medium with a 'low' concentration of sodium (i.e. $55 \mathrm{~mm}$ ) compared with those in medium with a 'normal' concentration of sodium (i.e. $124 \mathrm{~mm}$; Van Winkle, 1977, 1981); (3) trophoblastic outgrowth occurs in vitro unless the medium lacks certain amino acids or glucose (Gwatkin, 1966; Wordinger \& Brinster, 1976; Naeslund, 1979; Van Blerkom et al., 1979); and (4) attachment and outgrowth of blastocysts seem to be dependent on the concentrations of sodium, potassium and calcium in the medium and it appears that concentrations of these ions in uterine fluid change at the time of implantation (Clemetson, Kim, Mallikarjuneswara \& Wilds, 1972; Aitken, 1974; Van Blerkom et al., 1979; Van Winkle, 1981; Van Winkle, Campione \& Webster, 1983).

Although these findings are compatible with the hypothesis that embryonic quiescence is maintained in vivo by the limitation of some critical component of uterine fluid, in reality they are difficult to interpret because the failure of blastocysts to grow-out, or to show expected increases in metabolic activity, over relatively long periods in vitro could be the appropriate response to duplicas: 
tion in vitro of conditions within the delayed implanting uterus, or the result of non-specific deleterious effects of deficient culture medium.

In the present experiments, delayed implanting blastocysts were incubated in various 'deficient' media with the expectation that, if it is true that limitation of certain ions or organic substrates is the mechanism by which embryos are rendered dormant in vivo, it should be possible to maintain their quiescence in vitro without damage. The incorporation of $\left[{ }^{3} \mathrm{H}\right]$ thymidine into DNA was selected as a measure of metabolic activity since it is almost completely suppressed in dormant embryos but increases rapidly as they are reactivated in vivo or in vitro (McLaren, 1973; Given \& Weitlauf, 1982).

\section{Materials and Methods}

Preparation of embryos. Mature virgin Swiss albino mice (Laboratory Supply Co., Indianapolis, IN) were induced to ovulate with gonadotrophins (Fowler \& Edwards, 1957) and placed with fertile males. The presence of a vaginal plug the following morning was taken as evidence of mating (designated Day 1). Normally implanting blastocysts were recovered between $09: 00$ and 12:00 h on Day 5. Delayed implanting embryos were produced by ovariectomizing mice between $09: 00$ and $12: 00 \mathrm{~h}$ on Day 4 , and injecting $2 \mathrm{mg}$ progesterone subcutaneously on Days 7-9; embryos were collected on Day 10. Embryos activated in vivo were obtained by injecting $25 \mathrm{ng}$ oestradiol-17ß into delayed implanting mice on Day 9 (i.e. $24 \mathrm{~h}$ before embryo recovery on Day 10).

Complete and deficient media. Embryos were preincubated in complete medium, or one of several deficient media, for various periods of time before being pulsed with $\left[{ }^{3} \mathrm{H}\right]$ thymidine to determine whether they would remain dormant. It was reasoned that if limitation of some simple component of uterine fluid was responsible for embryo dormancy in vivo, then its absence from the medium would prevent activation in vitro. Conversely, if the limitation of a particular ion or molecule in vivo is not responsible for dormancy, then embryos should become reactivated regardless of its presence or absence in vitro. The media tested (Table 1) were Medium A, a complete medium consisting of Eagle's basic medium (BME) containing amino acids, glucose and vitamins, and several deficient media: Medium B, BMOC-3 which contains no amino acids or vitamins (Brinster, 1971); Medium C, BMOC-3 with glucose but without pyruvate and lactate (i.e. restricted substrates); Medium D, BMOC-3 without glucose, pyruvate or lactate (i.e. no metabolizable substrate); Medium E, BMOC-3 with reduced $\mathrm{Na}^{+}$(55 mM compared to $124 \mathrm{~mm}$ in normal BMOC-3); and Media F-I, a series of $25 \mathrm{~mm}$-bicarbonate buffer solutions with varied $\mathrm{Na}^{+}$and $\mathrm{K}^{+}$but no metabolizable components or other ions (except $\mathrm{Cl}^{-}$and choline to maintain osmotic balance).

Analysis of $\left[{ }^{3} \mathrm{H}\right]$ thymidine incorporation. Incorporation of $\left[{ }^{3} \mathrm{H}\right]$ thymidine was measured by a modification of the liquid scintillation method of Cozad, Verbanac, Goldbard \& Warner (1981). Preliminary studies were conducted to determine whether estimates of the magnitude and time course of change in the rate of incorporation of $\left[{ }^{3} \mathrm{H}\right]$ thymidine during reactivation by this method agreed with earlier reports using autoradiography. Embryos were placed in $200 \mu \mathrm{l}$ of labelling medium consisting of Eagle's basic medium (BME, Gibco, Grand Island, NY) with $8.5 \mathrm{mg}$ bovine serum albumin (BSA)/ml (Fraction V, Sigma Chemical Co., St Louis, MO), $0.28 \mu$ glutamine $/ \mathrm{ml}$, 100 i.u. penicillin $/ \mathrm{ml}, 50 \mu \mathrm{g}$ streptomycin $/ \mathrm{ml}$, and $5 \cdot 0 \mu \mathrm{Ci}\left[{ }^{3} \mathrm{H}\right]$ thymidine $/ \mathrm{ml}$ (sp. act. $50-80 \mathrm{Ci} / \mathrm{mmol}$ : New England Nuclear, Boston, MA). After labelling for $1 \mathrm{~h}$, the embryos (2-5 for each replicate) were washed once in cold medium and transferred to $20 \mu \mathrm{l}$ of a solution of $50 \mu \mathrm{g}$ calf thymus DNA/ml (used as a carrier) $; 0.5 \mathrm{ml}$ ice-cold $10 \%$ trichloroacetic acid (TCA) with $10 \mathrm{mM}$-potassium phosphate and $10 \mathrm{~mm}$-potassium pyrophosphate was added and the sample was allowed to precipitate for 15 min on ice. The precipitated material was collected on glass fibre filters; the filters were air dried and placed in scintillation vials. Precipitated material was solubilized for $30 \mathrm{~min}$ at $65^{\circ} \mathrm{C}$ with $0.5 \mathrm{ml}$ Protosol (New England Nuclear). This was allowed to cool to room temperature 
and $20 \mu \mathrm{l}$ glacial acetic acid were added, followed by $10 \mathrm{ml}$ scintillation cocktail (PPO-POPOP in toluene); ${ }^{3} \mathrm{H}$ counts were then measured in a scintillation counter with a counting efficiency of approximately $39 \%$. Background counts were measured in a sample of the wash medium and subtracted from counts in the embryos (always $<50$ c.p.m.). Incorporation of thymidine is expressed as net c.p.m./embryo/h.

Estimates of rates of incorporation of $\left[{ }^{3} \mathrm{H}\right]$ thymidine into DNA by this method are summarized in Text-fig. 1, and compared to values obtained for labelling index by autoradiography in previous experiments (Given \& Weitlauf, 1981, 1982). Results obtained by both methods agree and demonstrate that reactivation of dormant embryos in vivo (i.e. after injection of oestrogen) results in rates of $\left[{ }^{3} \mathrm{H}\right]$ thymidine incorporation essentially equal to that found in active embryos implanting normally on Day 5 . An apparently similar process was observed in vitro as early as $12 \mathrm{~h}$ after recovering the embryos and continued for at least $72 \mathrm{~h}$. That the $\left[{ }^{3} \mathrm{H}\right]$ thymidine was incorporated into DNA was inferred from the fact that treatment of the samples with DNase (Type II, Calbiochem, LaJolla, CA) reduced acid-precipitable counts by more than $90 \%$.

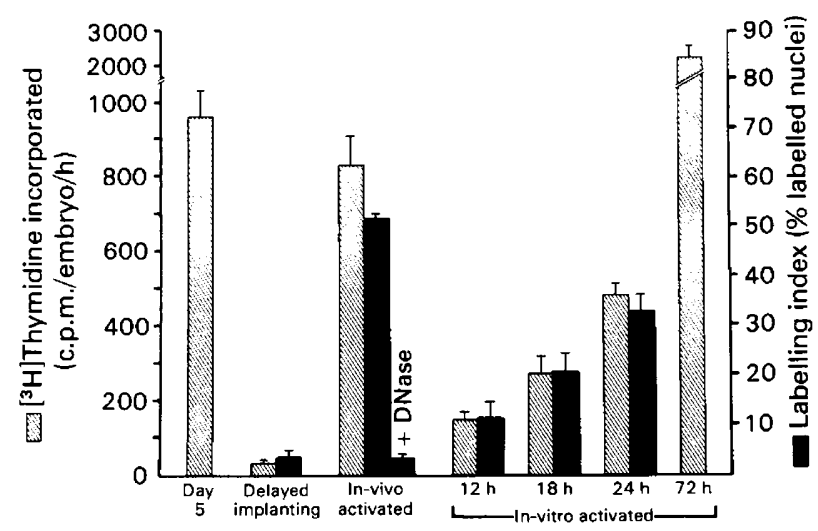

Text-fig. 1. Comparison of liquid scintillation counting and autoradiographic methods measuring $\left[{ }^{3} \mathrm{H}\right]$ thymidine incorporation in dormant and reactivated mouse blastocysts. Normally implanting Day- 5 embryos, delayed implanting embryos, and reactivated embryos (in vivo after oestrogen administration or in vitro after preincubation in medium for up to $72 \mathrm{~h}$ ) were incubated in $\left[{ }^{3} \mathrm{H}\right]$ thymidine and analysed for TCA-precipitable incorporation as described in 'Materials and Methods'. These values are compared to those previously reported using autoradiographic analysis of labelled nuclei (Given \& Weitlauf, 1981, 1982). Values are means \pm s.e.m. of 6-12 determinations for each group.

In experiments testing the effects of glucose, amino acid and ion-deficient media, $\left[{ }^{3} \mathrm{H}\right]$ thymidine pulsing was carried out in complete BMOC-3 (Brinster, 1971) with $8.5 \mathrm{mg} \mathrm{BSA} / \mathrm{ml}$, penicillin and streptomycin, and $5 \mu \mathrm{Ci}\left[{ }^{3} \mathrm{H}\right]$ thymidine $/ \mathrm{ml}$. Precipitation and counting of incorporated $\left[{ }^{3} \mathrm{H}\right]$ thymidine was done as described above.

\section{Results}

\section{Effects of limiting energy source and amino acids}

Delayed implanting blastocysts incubated in Media B, C, or D had rates of $\left[{ }^{3} \mathrm{H}\right]$ thymidine incorporation that were greater than those at $0 \mathrm{~h}$ (Table 1 ). The pattern of activation in Medium $B$ was identical to that in Medium A, indicating that lack of amino acids had no effect. Elimination of lactate and pyruvate from BMOC-3 (Medium C) resulted in a reduced level of activation, although removal of glucose (Medium D) had no further effect up to $18 \mathrm{~h}$. By $24 \mathrm{~h}$, incorporation of 
Table 1. $\left[{ }^{3} \mathrm{H}\right]$ Thymidine incorporation into mouse embryos in complete and deficient media

\begin{tabular}{|c|c|c|c|c|c|c|c|c|}
\hline & \multirow[b]{3}{*}{ Medium* } & \multirow{2}{*}{\multicolumn{3}{|c|}{ Conc. of: }} & \multicolumn{4}{|c|}{$\left[{ }^{3} \mathrm{H}\right]$ Thymidine incorporation $\dagger$} \\
\hline & & & & & \multicolumn{4}{|c|}{ Preincubation time } \\
\hline & & $\begin{array}{l}\mathrm{Na}^{+} \\
(\mathrm{mM})\end{array}$ & $\begin{array}{c}\mathrm{K}^{+} \\
(\mathrm{mM})\end{array}$ & $\begin{array}{l}\text { Glucose } \\
\text { (mM) }\end{array}$ & $0 \mathrm{~h}$ & $12 \mathrm{~h}$ & $18 \mathrm{~h}$ & $24 \mathrm{~h}$ \\
\hline A & $\begin{array}{l}\text { (BME-Earle's salts solution } \\
\text { with amino acids and vitamins) }\end{array}$ & 140 & 6 & $5 \cdot 5$ & $35 \underset{(12)}{ \pm}$ & $144 \underset{(12)}{ \pm 21}$ & $271 \pm{ }_{(10)}^{ \pm 44^{\mathrm{ab}}}$ & $479 \underset{(12)}{ \pm} 30$ \\
\hline B & $\begin{array}{l}\text { (BMOC-3-balanced salts } \\
\text { solution with glucose, lactate } \\
\text { and pyruvate) }\end{array}$ & 125 & 5 & $5 \cdot 5$ & $26 \pm \frac{6}{(12)}$ & $184 \underset{(10)}{ \pm 22}$ & $292 \pm 27^{a}$ & $467 \underset{(12)}{ \pm} 65$ \\
\hline $\mathrm{C}$ & $\begin{array}{l}\text { (BMOC-3 without pyruvate or } \\
\text { lactate) }\end{array}$ & 125 & 5 & $5 \cdot 5$ & $39 \pm 9$ & -- & $196 \pm 26^{\mathrm{abc}}$ & $248 \pm \frac{22}{(7)}$ \\
\hline D & $\begin{array}{l}\text { (BMOC-3 without glucose, } \\
\text { pyruvate or lactate) }\end{array}$ & 125 & 5 & 0 & $48 \underset{(7)}{ \pm} 14$ & - & $198 \pm 32^{\mathrm{abc}}$ & $187 \underset{(8)}{ \pm} 28$ \\
\hline $\mathbf{E}$ & (BMOC-3 with low sodium) & 55 & 5 & $5 \cdot 5$ & $21 \pm \frac{ \pm}{(9)}$ & - & - & $287 \underset{(13)}{ \pm}$ \\
\hline $\mathbf{F}$ & $\begin{array}{l}\text { ( } 25 \mathrm{~mm} \text {-bicarbonate buffer } \\
\text { with high } \mathrm{Na}^{+} \text {and } \mathrm{K}^{+} \text {) }\end{array}$ & 125 & 6 & 0 & - & $86 \underset{(10)}{ \pm} 19$ & $265 \underset{(10)}{ \pm 26^{\mathrm{ab}}}$ & - \\
\hline G & $\begin{array}{l}\text { ( } 25 \text { mM-bicarbonate with low } \\
\mathrm{Na}^{+} \text {and high } \mathrm{K}^{+} \text {) }\end{array}$ & 55 & 6 & 0 & - & $77 \underset{(7)}{ \pm} 12$ & $121 \pm 21^{c}$ & - \\
\hline $\mathbf{H}$ & $\begin{array}{l}(25 \text { mm-bicarbonate with high } \\
\left.\mathrm{Na}^{+} \text {and low } \mathrm{K}^{+}\right)\end{array}$ & 125 & 3 & 0 & - & $88 \underset{(7)}{ \pm} 33$ & $212 \underset{(8)}{ \pm} 57^{\mathrm{abc}}$ & - \\
\hline I & $\begin{array}{l}(25 \text { mM-bicarbonate with low } \\
\mathrm{Na}^{+} \text {and } \mathrm{K}^{+} \text {) }\end{array}$ & 55 & 3 & 0 & - & $62 \underset{(7)}{ \pm} 16$ & $142 \pm 28^{\mathrm{bc}}$ & - \\
\hline
\end{tabular}

- All media contained $8.5 \mathrm{mg} \mathrm{BSA} / \mathrm{ml}$, penicillin/streptomycin and were gassed with $5 \% \mathrm{CO}_{2}$ in air.

† Values are mean \pm s.e.m. with the no. of replicates in parentheses. Data at $18 \mathrm{~h}$ were subjected to analysis of variance and compared with Student-Newman-Keuls multiple range test; values with different superscript letters are significantly different $(P<0.05)$.

$\left[{ }^{3} \mathrm{H}\right]$ thymidine began to decrease in glucose-free medium (Medium D). In contrast, it continued to increase between 18 and $24 \mathrm{~h}$ in embryos incubated in Medium C (containing glucose).

\section{Effects of concentrations of various ions}

Incubation of delayed implanting embryos in Medium $\mathrm{E}$ (low $\mathrm{Na}^{+}$) for $24 \mathrm{~h}$ resulted in a significant increase in $\left[{ }^{3} \mathrm{H}\right]$ thymidine incorporation (Text-fig. 2 ), although the magnitude was less than that in Medium B with the normal concentration of $\mathrm{Na}^{+}$. In Medium $\mathrm{B}$ the increase in DNA synthesis continued through $48 \mathrm{~h}$, while in Medium $\mathrm{E}$ it decreased between 24 and $48 \mathrm{~h}$. Transfer of embryos from low $\mathrm{Na}^{+}$to high $\mathrm{Na}^{+}$after $24 \mathrm{~h}$ did not restore incorporation to control levels although it did prevent the further reduction observed with continued exposure to low $\mathrm{Na}^{+}$(Text-fig. 2). Blastocysts in low $\mathrm{Na}^{+}$were collapsed at $48 \mathrm{~h}$ and transfer to normal medium after $48 \mathrm{~h}$ failed to restore incorporation rate or normal morphology. Therefore, quiescent embryos incubated in low $\mathrm{Na}^{+}$(Medium E) not only failed to remain dormant with respect to DNA synthesis, but after $24 \mathrm{~h}$ in that medium they appeared to be irreversibly damaged.

A second set of experiments was done to determine whether activation would occur in the absence of other ions commonly found in embryo culture media (Table 1). Significant increases in $\left[{ }^{3} \mathrm{H}\right]$ thymidine incorporation were observed at 12 and $18 \mathrm{~h}$ in Medium F consisting of only $25 \mathrm{~mm}$ bicarbonate buffer, $125 \mathrm{mM}-\mathrm{Na}^{+}, 6 \mathrm{mM}-\mathrm{K}^{+}$and BSA. The magnitude of increase was less than that found in Media A and B, and by $24 \mathrm{~h}$ many of the embryos were collapsed. Extensive dialysation of BSA in the medium (to remove possible contributions of metabolities and ions from this source) did 


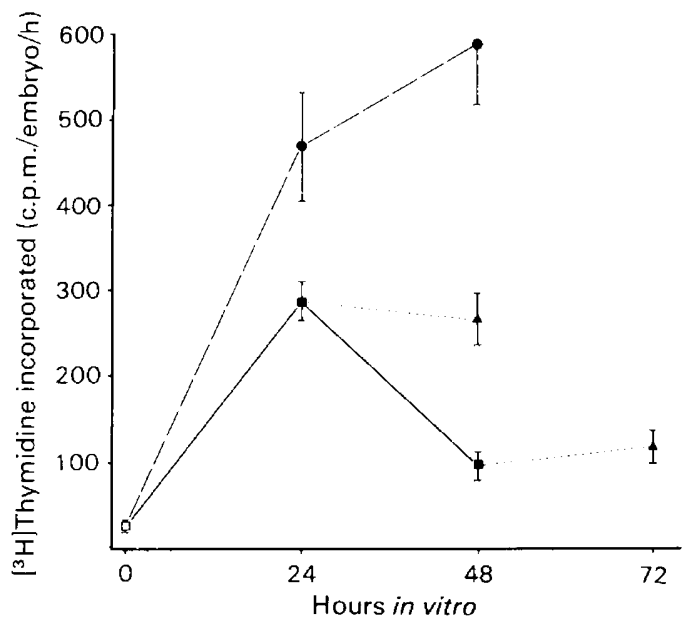

Text-fig. 2. Effects of limited $\mathrm{Na}^{+}$on activation of dormant mouse embryos in vitro. Delayed implanting embryos were incubated in $124 \mathrm{mM}-\mathrm{Na}^{+}\left(\mathbf{O}_{---}\right)$or $55 \mathrm{mM}^{-\mathrm{Na}^{+}}(\boldsymbol{\square}-\boldsymbol{\square})$ for up to $48 \mathrm{~h}$, then analysed for $\left[{ }^{3} \mathrm{H}\right]$ thymidine incorporation. At 24 and $48 \mathrm{~h}$, some low $\mathrm{Na}^{+}$ embryos were transferred to high $\mathrm{Na}^{+}$medium and assayed $24 \mathrm{~h}$ later (-...-...

not significantly change the degree of activation observed at $12 \mathrm{~h}(114 \pm 27$ c.p.m./embryo/h, $n=5$ ). Reduction of $\mathrm{Na}^{+}$to $55 \mathrm{mM}$ (Medium G), $\mathrm{K}^{+}$to $3 \mathrm{~mm}$ (Medium $\mathrm{H}$ ), or both (Medium I), did not prevent the initial increase in thymidine incorporation. However, these ion reductions resulted in an even quicker deterioration of the embryos and approximately one-half of the blastocysts in Medium I were collapsed by $18 \mathrm{~h}$.

\section{Discussion}

Measurements of incorporation of $\left[{ }^{3} \mathrm{H}\right]$ thymidine into DNA by a liquid scintillation counting method confirmed that activation of DNA synthesis occurs in dormant embryos incubated in complete medium in vitro. The time course and relative magnitude of activation in Eagle's basal medium was similar to that previously reported for activation in this medium using an autoradiographic technique to determine changes in labelling index (Given \& Weitlauf, 1982).

Incubation of dormant blastocysts in media simpler than BME did not effectively prevent them from becoming reactivated. In all cases significant increases in $\left[{ }^{3} \mathrm{H}\right]$ thymidine incorporation were observed within the first $24 \mathrm{~h}$ of culture. There were, however, differences in the magnitude of this increase as well as the continued viability of the embryos in the more severely deficient media. Activation in BMOC-3 (Medium B) resulted in rates of incorporation at $24 \mathrm{~h}$ nearly equal to those of embryos incubated in BME. Since BMOC-3 lacks the amino acids and vitamins present in BME, it appears that absence of these substances is not sufficient to maintain embryo dormancy in vitro. This was expected since activation of $\left[{ }^{3} \mathrm{H}\right]$ uridine incorporation in dormant embryos has also been shown to occur in BMOC-3 (Weitlauf, 1976). Similarly, removal of pyruvate and lactate from BMOC-3 (Medium C) did not prevent activation during the first $24 \mathrm{~h}$ of incubation, although the increase in thymidine incorporation was less than that seen in complete BMOC-3. The beneficial effects of pyruvate and lactate on mouse embryo survival and development in vitro (Biggers \& Stern, 1973) apparently extend through the implantation period, but do not seem to be involved in maintaining embryo quiescence. Removal of glucose, as well as pyruvate and lactate from BMOC-3 (Medium D) did not prevent activation and the magnitude of activation up to $18 \mathrm{~h}$ was not affected. After $18 \mathrm{~h}$, however, embryos in substrate-free medium showed a decrease in thymidine incorporation. This indicates that initiation of activation is not dependent on an external energy 
source and, in the absence of metabolizable substrates, synthetic activity can be fuelled by endogenous energy stores, presumably glycogen (Ozias \& Weitlauf, 1971). However, after $18 \mathrm{~h}$ in these conditions this energy reserve may be depleted, thus explaining the apparent dormancy of blastocysts in long-term culture without glucose and amino acids (Wordinger \& Brinster, 1976; Van Blerkom et al., 1979; Naeslund, 1979). In addition, Nieder \& Weitlauf (1984) have demonstrated that delayed implanting blastocysts are actually in a high energy state (i.e. a high ATP/ADP ratio), a condition that is not compatible with energy substrate starvation. Starvation-induced dormancy therefore does not seem to be analogous to the dormancy of delayed implantation in vivo.

The ionic requirements for metabolic activation appear to be very minimal and do not readily suggest a means of uterine control over the embryo. Reduction of $\mathrm{Na}^{+}$to $55 \mathrm{~mm}$ in BMOC-3 (Medium E) did not prevent activation although the absolute increase in thymidine incorporation at $24 \mathrm{~h}$ was lower than in BMOC-3 with normal $\mathrm{Na}^{+}$. This is in disagreement with the findings of Van Winkle $(1977,1981)$ in which the increase in labelled amino acid incorporation expected with activation was prevented by incubation in medium with $55 \mathrm{mM}-\mathrm{Na}^{+}$. However, since uptake of amino acids, as well as their incorporation, is depressed in delayed or normal Day- 5 embryos pulsed for $2 \mathrm{~h}$ in low $\mathrm{Na}^{+}$(Van Winkle, 1977, 1981), the specific activities of amino acid pools in these embryos may be variable. Conclusions about the effects of $\mathrm{Na}^{+}$on protein synthetic rates based on incorporation of label under these conditions should be made with great care. Further, Van Winkle (1981) has proposed that 'low' $\mathrm{Na}^{+}$maintains a dormancy in vitro analogous to that occurring in utero by limiting $\mathrm{Na}^{+}$-dependent amino acid transport necessary for activation. The present work has demonstrated that activation of DNA synthesis is independent of exogenous amino acids so that inhibition of amino acid transport by limited $\mathrm{Na}^{+}$would not prevent activation in vitro or presumably in vivo. The observation of Van Winkle (1981) that delayed implanting blastocysts kept in 'low' $\mathrm{Na}^{+}$for $24 \mathrm{~h}$ exhibited a slower rate of outgrowth when transferred to 'high' $\mathrm{Na}^{+}$medium compared to newly collected delayed embryos may reflect a non-specific deleterious effect of 'low' $\mathrm{Na}^{+}$conditions. In the present study 'low' $\mathrm{Na}^{+}$decreased the magnitude of activation during the first $24 \mathrm{~h}$ and produced irreversible damage in the embryos. Incubation in 'low' $\mathrm{Na}^{+}$for longer than $24 \mathrm{~h}$ resulted in the death of the embryos. It seems probable that a delay of outgrowth for longer periods by 'low' $\mathrm{Na}^{+}$medium would not be reversible; no data have appeared in the literature on this point.

Other ionic species present in BME and BMOC-3 such as calcium, magnesium, potassium and phosphate have been implicated in the control of cell proliferation (Hickie, Wei, Blyth, Wong \& Klaassen, 1983; Engstrom \& Zetterberg, 1983) and implantation (Clemetson et al., 1972; Aitken, 1974; Van Blerkom et al., 1979). Metabolic dormancy in delayed implanting embryos does not seem to be dependent on the concentration of these ions in the external environment since significant activation occurred in bicarbonate buffer with $\mathrm{NaCl}$ and $\mathrm{KCl}$ and no other salts (Medium $\mathrm{F}$ ). Further, decreasing $\mathrm{Na}^{+}$or $\mathrm{K}^{+}$, or both (Media $\mathrm{G}, \mathrm{H}$ and I) did not totally prevent activation, although the viability of embryos under these severely restricted conditions was compromised quickly. This was reflected in the morphological appearance of the embryos and greater variability in incorporation rates in these groups.

The conclusion drawn from these experiments is that the metabolic quiescence of delayed implanting blastocysts is not maintained in vitro by the limitation of metabolizable substrates, or particular ionic species in the medium. Indeed, activation proceeds under many conditions that will not support embryo development or even survival for more than a few hours. These observations limit the possibilities for uterine control over the blastocyst during delayed implantation. It now seems unlikely that changes in the availability of organic substrates or ionic environment in the uterine lumen are the controlling factor in initiation of metabolic activation. An alternative explanation may be the presence of inhibitory substances in the uterus during delayed implantation which are removed after administration of oestrogen or by transfer of embryos to an in-vitro environment (Psychoyos, Bitton-Casimiri \& Brun, 1975; Weitlauf, 1976; O'Neill \& Quinn, 1983). This possibility is being explored. 
This work was supported by grant HD 17437-02 from the National Institute of Child Health and Human Development.

\section{References}

Aitken, R.J. (1974) Calcium and zinc in the endometrium and uterine flushings of the roe deer (Capreolus capreolus) during delayed implantation. J. Reprod. Fert. 40, 333-340.

Biggers, J.D. \& Stern, S. (1973) Metabolism of the preimplantation mammalian embryo. Adv. Reprod. Physiol. 6, 1-59.

Brinster, R.L. (1971) In vitro culture of the embryo. In Pathways to Conception: the Role of the Cervix and the Oviduct in Reproduction, pp. 245-277. Ed. A. I. Shermen. Charles C. Thomas, Springfield.

Clemetson, C.A.B., Kim, J.K., Mallikarjuneswara, V.R. \& Wilds, J.H. (1972) The sodium and potassium concentrations in the uterine fluid of the rat at the time of implantation. J. Endocr. 54, 417-423.

Cozad, K.M., Verbanac, K.M., Goldbard, S.B. \& Warner, C.M. (1981) An automated procedure to measure DNA synthesis in preimplantation mouse embryos. Gamete Res. 4, 121-131.

Engstrom, W. \& Zetterberg, A. (1983) Phosphate and the regulation of DNA replication in normal and virustransformed 3T3 cells. Biochem. J. 214, 695-702.

Fowler, R.E. \& Edwards, R.G. (1957) Induction of superovulation and pregnancy in mature mice by gonadotrophins. J. Endocr. 15, 374-384.

Given, R.L. \& Weitlauf, H.M. (1981) Resumption of DNA synthesis during activation of delayed implanting mouse embryos. J. exp. Zool. 218, 253-259.

Given, R.L. \& Weitlauf, H.M. (1982) Resumption of DNA synthesis in delayed implanting mouse blastocysts during activation in vitro. J. exp. Zool. 224, 111114.

Gwatkin, R.B.L. (1966) Defined media and the development of mammalian eggs in vitro. Ann. N.Y. Acad. Sci. 137, 79-90.

Hickie, R.A., Wei, J.-W., Blyth, L.M., Wong, D.Y.W. \& Klaassen, D.J. (1983) Cations and calmodulin in normal and neoplastic cell growth regulation. Can.J. Biochem. Cell Biol. 61, 934-941.

McLaren, A. (1973) Blastocyst activation. In The Regulation of Mammalian Reproduction, pp. 301-330. Eds S. J. Segal, P. A. Corfman \& P. G. Condliffe. Charles C. Thomas, Springfield.

Naeslund, G. (1979) The effect of glucose-, arginine-, and leucine-deprivation on mouse blastocyst outgrowth in vitro. Uppsala J. med. Sci. 84, 9-20.
Nieder, G.L. \& Weitlauf, H.M. (1984) Regulation of glycolysis in the mouse blastocyst during delayed implantation. J. exp. Zool. 231, 121-129.

O'Neill, C. \& Quinn, P. (1983) Inhibitory influence of uterine secretions on mouse blastocysts decreases at the time of blastocyst activation. J. Reprod. Fert. 68, 269-274.

Ozias, C.B. \& Weitlauf, H.M. (1971) Hormonal influences on the glycogen content of normal and delayed implanting mouse blastocysts. J. exp. Zool. 177, 147-152.

Psychoyos, A.V., Bitton-Casimiri, V. \& Brun, J.L. (1975) Repression and activation of the mammalian blastocyst. In Regulation of Growth and Differentiated Function in Eukaryotic Cells, pp. 509-514. Ed. G. P. Talwar. Raven Press, New York.

Van Blerkom, J., Chavez, D.J. \& Bell, H. (1979) Molecular and cellular aspects of facultative delayed implantation in the mouse. In Maternal Recognition of Pregnancy (Ciba Symposium No. 64), pp. 141-172. Ed. J. Whelan. Elsevier-Excerpta Medica-North Holland, Amsterdam.

Van Winkle, L.J. (1977) Low $\mathrm{Na}^{+}$concentration : a factor contributing to diminished uptake and incorporation of amino acids by diapausing mouse blastocysts? $J$. exp. Zool. 202, 275-281.

Van Winkle, L.J. (1981) Activation of amino acid accumulation in delayed implantation mouse blastocysts. J. exp. Zool. 218, 239-246.

Van Winkle, L.J., Campione, A.L. \& Webster, D.P. (1983) Sodium ion concentrations in uterine flushings from "implanting" and "delayed implanting" mice. J. exp. Zool. 226, 321-324.

Weitlauf, H.M. (1976) Effect of uterine flushings on RNA synthesis by 'implanting' and 'delayed implanting' mouse blastocysts in vitro. Biol. Reprod. 14, 566571.

Wordinger, R.J. \& Brinster, R.L. (1976) Influence of reduced glucose levels on the in vitro hatching, attachment and trophoblast outgrowth of the mouse blastocyst. Devl Biol. 53, 294-296. 